\title{
Toward Exploring Errors in Grammar: A Systematic Approach for Language Teachers
}

Caroline M.L. Ho

This article focuses on an attempt by a teacher education institute to empower non-English majors to teach English at the primary level, drawing on a preservice English-language teacher education program for undergraduates at the National Institute of Education, Singapore. The course, which has been running for three years, aims to develop student teachers' skills in analyzing grammatical features in primary-level writing, based on a three-step approach designed by the author specifically for non-English majors. The article also explores the difficulties that student teachers face in learning to identify, classify, and explain various types of errors, including suggestions on how to empower student teachers to help primary-level pupils understand and use grammar rules effectively.

Cet article porte sur les démarches entreprises par une institution de formation des enseignants et touchant des étudiants du premier cycle à la National Institute of Education, à Singapour. Le projet vise des stagiaires qui n'étudiaient pas l'anglais comme spécialité; l'institution a voulu les former de sorte à ce qu'ils puissent enseigner l'anglais au primaire. L'objectif du cours, qui a commencé il y a trois ans, est de développer chez les futurs enseignants des habiletés d'analyse grammaticale. L'auteure a développé une approche à trois étapes, conçue spécifiquement pour les étudiants n'ayant pas l'anglais comme spécialité, et qui vise l'analyse grammaticale des rédactions des élèves du primaire. L'article porte également sur les difficultés auxquelles sont confrontés les futurs enseignants dans leur apprentissage de l'identification, la classification et l'explication de divers types d'erreurs, et offre des suggestions pour appuyer les futurs enseignants dans leur enseignement de l'usage efficace des règles de grammaire.

\section{Introduction}

The study of English grammar is considered "an important aspect in the learning of English" in Singapore (Ministry of Education, 2001, p. 43); thus one of the aims of the English language (EL) syllabus is to enable pupils to "speak, write and make presentations in internationally acceptable English that is grammatical, fluent and appropriate for purpose, audience, context and culture," and so teachers' "knowledge of grammar and how it functions" is acknowledged to contribute to "effective language use" (pp. 3, 6). 
This article draws on a preservice English-language teacher training module in Singapore in the Curriculum Content or-as recently renamedthe Subject Skills Knowledge course aimed at developing student teachers' skills in analyzing and explaining grammar problems in the writing of primary pupils (age range 7-12 years). The module builds on student teachers' knowledge of basic English grammar, introduced in an earlier grammar foundation course, and seeks to help them apply this knowledge to children's writing. It should be noted that this module focuses only on sentencelevel grammar and does not attempt to address discourse-level errors.

This account examines a systematic approach to error analysis that I designed specially to promote the identification and analysis of students' errors and the explanation of the grammar rules involved, along with consideration of its effects on student teachers who were trained in this approach for the first time. Although such attention to grammar errors is not in itself a new practice, there is a dearth of studies investigating the effect on student teachers of explicit teacher education regarding grammar error and analysis, and the implications for classroom language practitioners in this area have not been much discussed. Also explored are the difficulties of student teachers learning to identify, classify, and explain types of grammar errors in children's writing, along with recommendations on how to empower student teachers to help primary-level students understand and use grammar rules effectively

\section{The Place of Error Analysis in Language Teaching}

Ever since Corder (1967) highlighted the importance of considering errors in the language-learning process, there has been a shift in the understanding of the problems learners face in their study of a language: errors are indispensable to learners because making errors can be regarded as "a device the learner uses in order to learn" (Selinker, 1992, p. 150). Research has provided empirical evidence emphasizing learners' errors as an effective step toward improving grammatical accuracy (White, Spada, Lightbown, \& Ranta, 1991; Carroll \& Swain, 1993; Trahey \& White, 1993). Indeed, as Carter (1997) notes, "Knowing more about how grammar works is to understand more about how grammar is used and misused" (p. 35). Students need to recognize the significance of errors in their own writing and to understand their nature fully. This requires English-language teachers to be sensitive to and aware of pupils' difficulties with regard to grammar.

In this article, I distinguish mistakes from errors. The former refer to erratic inaccuracies as opposed to systematic errors from which one may reconstruct learners' developing knowledge of the language (Corder, 1981). If students' grammar errors are systematic and classifiable, attention to error types and understanding of the violation or misuse of specific grammar rules can offer language teachers a useful means of helping students deal with 
language and use problems so as to sensitize learners to specific problems they may have and to enable their recognition and remediation.

\section{Background of the Grammar Course for Non-English Majors}

English majors taking undergraduate degree programs at the National Institute of Education, Singapore have all along been offered modules in their academic studies courses that specifically focus on studies of grammar and grammar-related issues. However, a growing need was recognized to enhance all language teachers' proficiency in the use of English. This was seen as particularly critical for non-English majors in the generalist primary teacher preparation program, which trains candidates to teach three subjects, one of which is English, because they would have received less exposure to English grammar since leaving school than their English major counterparts. English has been a compulsory subject for all schools in Singapore since 1966, and since 1987 it has been the medium of instruction for all subjects. It has been assigned a key role in the modernization and socioeconomic development of Singapore and is regarded as the "major language of administration, commerce, education, and consequently, social status" (Gopinathan, 1999, p. 21). English has for all practical purposes become the lingua franca for the linguistically diverse population of Singapore; however, although English would have been the main medium of instruction during these teachers' education, it may not be their dominant home language.

The Ministry of Education, in collaboration with the University of Cambridge Local Examinations Syndicate, recognized the gap between English and non-English majors in terms of their grammar foundations and sought to address the challenge of equipping all English-language teachers with the necessary skills. Grammar-upgrading courses were mounted nation-wide. Inservice refresher courses were made compulsory for practicing teachers; with respect to preservice student teachers, there was similar concern as to the command of English of those who would ultimately be teaching English in schools. A further push toward a foundation course in grammar came from the Ministry of Education when the revised English language syllabus was implemented in 2001: the English Language Syllabus 2001 for Primary and Secondary Schools integrated language teaching with text types; this highlighted the need for a foundational platform to recognize language features associated with various text types, which in turn required teachers to have a firm grounding in English grammar. The Ministry of Education emphasized explicit grammar teaching with a focus on accuracy rather than mere fluency: knowledge of grammar was considered essential for effective language use, and teachers were encouraged to give pupils "the 'metacognitive edge' - to be able ... to distinguish what is grammatical and what isn't' (Lim, 2000, p. 14). Furthermore, language-teaching methodology courses in teacher education programs tended to assume that student teach- 
ers had a working knowledge of English grammar adequate for language teaching, which was far from the truth. Thus from the 2005-2006 academic year, all student teachers have been required to take a course in Language Enhancement and Academic Discourse Skills; also, content upgrading courses with a focus on grammar and language use are mounted during the vacation for student teachers about to begin their preservice teacher education programs.

\section{Information on the Course}

The compulsory course Introduction to the English Language was a 24-hour, 12-week module with weekly two-hour tutorials without mass lectures. Using the online Blackboard platform facilitated the dissemination of tutorial tasks and activities and the uploading of worksheets, practice exercises, and answers. All tutors and staff had easy access to the online course materials before each week's tutorials.

Participants were non-English major students (i.e., they were majors in geography, history, mathematics, physics, chemistry, biology, or physical education) in an undergraduate BA/BSc (education) program preparing them to teach at the primary level. The cohort of 89 students cut across years 1 to 4 of undergraduate study. Most of the participants, however, were first-year undergraduates; the rest were returning teachers, that is, non-graduate teachers who had been teaching for some time and had returned to the university having been identified for the opportunity to pursue a BA/BSc (education) degree. These mature students had already gone through the compulsory basic grammar foundation courses $(60 \mathrm{hrs})$ while teaching in schools. A number were experienced teachers, senior teachers, subject heads, or heads of departments. All course participants would graduate from the program as primary generalists equipped to teach three subjects: English, mathematics, and a third subject: science, social studies, physical education, music, or art.

The course workbook Exploring Errors in grammar: A Guide for English Language Teachers $(\mathrm{Ho}, 2005)$ presents the approach that I designed; student teachers in the program are also allowed to refer to another grammar reference book of their choice: Willis' (1991) Collins COBUILD Student's Grammar or Crystal's (1998) Rediscover Grammar. Part of the formative assessment in the course-to familiarize student teachers with the approach and to build their confidence progressively-is a series of in-class mock tests based on the approach in question adapted to grammar topics covered in the course. A two-hour final assessment (worth 100\%) is administered to all student teachers. The assessment is open-book format, with student teachers allowed to refer to grammar reference books and the list of terminology used in the course. 


\section{Three-Step Approach to Error Identification and Analysis}

Throughout the course, the three-step approach that I devised is designed to enable identification and analysis of students' errors. The sections below outline the steps involved (see Appendix A for the table used for grammatical analysis).

1. Where is the problem? -Identification of errors

Write out the sentence containing the error. Underline/highlight the word/phrase/clause which shows the error.

E.g., He are hungry.

Use a caret ${ }^{\wedge}$ to indicate omissions (if any).

E.g., He hit $\wedge$ car (omission of article a).

2. What is the type of problem?-Definition and classification of errors

a) State type of error

E.g., Part of speech : e.g., Verb, article, noun, adjective, adverb, preposition.

b) Classify error type

E.g., Omission, overgeneralization, wrong combination.

E.g., He are hungry.

\begin{tabular}{lll}
\hline Error identified & Definition of error type & $\begin{array}{l}\text { Classification of error type } \\
\text { He are hungry. }\end{array}$ \\
& Verb & $\begin{array}{l}\text { Wrong combination of subject } \\
\text { and verb. }\end{array}$ \\
\hline
\end{tabular}

3. How can you explain the problem?-Explanation of rule and

exemplification

a) State the grammar rule which has been violated.

E.g., Singular subject $H e$ must take a singular verb is.

b) Give the correct form to show contrast with the inappropriate/deviant form.

E.g., He is hungry.

c) Give other examples showing the rule in action.

E.g., She is tired.

Guiding Teachers in Adopting the Approach

A list of suggested terms was provided as a means of scaffolding and of equipping teachers with the terminology required to begin explaining the nature of the errors identified:

Definition of error types

- Noun

- Pronoun

- Verb 
- Conjunction

- Adjective

- Adverb

- Preposition

- Article

- Determiner

- Sentence structure

The term sentence structure was included for errors pertaining to sentence construction, for example, if a sentence is incomplete or fragmented: for example, Although it was raining. The boys continued playing in the field.

Classification of error types

The classification of error types was narrowed to the use of the following terms (see Appendix B for examples of classifications):

- Omissions

- Additions

- Over-/Double marking

- Overgeneralization

Unnecessary insertion

- Wrong or inappropriate combination

- Inappropriate construction

- Misordering or inversion

Explanation of rules

Where the explanation of rules is concerned, student teachers are taught to state the rules clearly and simply. The following are examples.

- The noun luggage is uncountable and is always in the singular form; thus luggages is unacceptable.

- A verb following the modal verb should is in the base form; hence should train is acceptable but not should trained.

- The subordinate clause "Although it is raining" is dependent on the main clause and cannot stand on its own. Thus Although it was raining, they continued playing is a complete sentence but Although it was raining is incomplete by itself.

\section{Applying the Approach to Sample Errors in Students' Writing}

The examples in Table 1 illustrate the use of the approach to deal with various errors in grammar. The classification of error type was facilitated by the use of broad terms such as omission, overgeneralization, or unnecessary insertion, which acted as prompts in guiding student teachers not only to explain the nature of the errors identified, but also to examine the errors closely in the context of the child's writing. The explanation of the rule referred student teachers to the original text where the error occurred, and it 
Table 1

Using the Three-Step Approach With Sample Errors in Students' Writing

\begin{tabular}{|c|c|c|}
\hline Identification of error & $\begin{array}{l}\text { Definition and error } \\
\text { classification }\end{array}$ & Explanation of rule \\
\hline $\begin{array}{l}\text { We put all the } \\
\text { equipments on the } \\
\text { beach. }\end{array}$ & $\begin{array}{l}\text { Noun } \\
\text { Unnecessary insertion of } \\
\text { plural marker } s\end{array}$ & $\begin{array}{l}\text { Equipment is an uncountable noun } \\
\text { and does not require the plural } \\
\text { marker } s \text { : We put all the equipment } \\
\text { on the beach. }\end{array}$ \\
\hline $\begin{array}{l}\text { A large number of } \\
\text { people is sick. }\end{array}$ & $\begin{array}{l}\text { Verb } \\
\text { Wrong combination of } \\
\text { subject and verb }\end{array}$ & $\begin{array}{l}\text { A large number refers to more than } \\
\text { one person, i.e., a plural subject, and } \\
\text { requires a plural verb are: } A \text { large } \\
\text { number of people are sick. }\end{array}$ \\
\hline $\begin{array}{l}\text { I would appreciate } \wedge \\
\text { if you could help me. }\end{array}$ & $\begin{array}{l}\text { Verb } \\
\text { Omission of direct object }\end{array}$ & $\begin{array}{l}\text { Appreciate is a transitive verb and } \\
\text { therefore needs a direct object } \\
\text { following it: I would appreciate it if } \\
\text { you could help me. }\end{array}$ \\
\hline $\begin{array}{l}\text { He is owing me ten } \\
\text { dollars. }\end{array}$ & $\begin{array}{l}\text { Verb } \\
\text { Inappropriate verb } \\
\text { construction }\end{array}$ & $\begin{array}{l}\text { Owe is a stative verb and does not } \\
\text { take the -ing participle form: He owes } \\
\text { me ten dollars. }\end{array}$ \\
\hline $\begin{array}{l}\text { I don't know why } \\
\text { are we taught this. }\end{array}$ & $\begin{array}{l}\text { Subject-verb order } \\
\text { Misordering/inversion of } \\
\text { subject and verb }\end{array}$ & $\begin{array}{l}\text { Subject-verb order inverted with verb } \\
\text { before subject (why are we taught) in } \\
\text { the direct question form, but with } \\
\text { subject we before verb are in the } \\
\text { indirect question form (why we are): I } \\
\text { don't know why we are taught this. }\end{array}$ \\
\hline $\begin{array}{l}\text { While she was } \\
\text { talking. The phone } \\
\text { rang. }\end{array}$ & $\begin{array}{l}\text { Sentence structure } \\
\text { Incomplete/fragmented } \\
\text { clause }\end{array}$ & $\begin{array}{l}\text { The subordinate clause While she } \\
\text { was talking is dependent on a main } \\
\text { clause and cannot stand on its own. } \\
\text { Thus While she was talking has to be } \\
\text { linked to the phone rang in order to } \\
\text { form a complete sentence. }\end{array}$ \\
\hline
\end{tabular}

required an understanding of the operation of the appropriate grammar rule in a specific context.

\section{Analysis and Discussion}

The data for this study were drawn from an end-of-course assessment that required student teachers to read a text written by a primary-level pupil, identify the grammatical errors, classify the type of errors, and explain the rules involved for each error identified (see Appendix C). The table that student teachers had used for analysis throughout the module was provided. The task was conducted in open-book mode, which allowed student teachers to refer to their notes and grammar reference books because the focus was on applying an approach rather than on assessment of their personal knowledge of grammar rules per se. Through quantitative and qualitative analyses 
of student teachers' answers, their strengths and difficulties in error analysis and explanation were identified and discussed.

\section{Error Definition and Classification}

Forty-six student teachers' scripts drawn from three tutorial groups selected at random were analyzed. Student teachers' answers regarding error definition and classification were identified, quantified, and categorized according to specific groupings (e.g., verb forms, noun forms, or sentence structure). Explanations of grammar rules were also examined for the nature and frequency of inaccurate answers in specific areas. Percentages of inaccurate responses in the various categories were then computed for a broad overview of the types of errors that posed difficulties for these student teachers.

The grammatical features representing various error types in the text under analysis included the following.

Verb-type. Tense, aspect, transitive verb requiring object, infinitive.

Adjective-type. Marking of article, adjectival form.

Noun-type. Singular/plural marking.

Sentence structure. Incomplete/fragmented complex sentence construction.

Table 2 shows the overall distribution and spread of error types in the pupil's essay that was the stimulus for the task. Verb-type errors formed half the total, followed by noun-type and sentence structure, with adjective-type representing the smallest proportion of errors.

I now turn to the first task in which student teachers were engaged: error identification and classification. Table 3 presents the types of grammar errors and the frequency of inaccurate identifications and classifications by student teachers. To reflect clearly the challenge to student teachers, percentage frequencies of inaccurate identifications and classifications were computed in relation to the maximum possible number of inaccurate responses in each category of grammar error, rather than by reference to the global total across all error types. This is particularly critical given the uneven distribution of types of grammar errors in the text, as shown in Table 2.

Table 2

Distribution and Spread of Error Types in the Stimulus Text

\begin{tabular}{lc}
\hline Nature of grammatical error & Percentage distribution in stimulus text \\
\hline Verb-type & 50 \\
Adjective-type & 12.5 \\
Noun-type & 18.75 \\
Sentence structure & 18.75 \\
Total & 100 \\
\hline
\end{tabular}


Table 3

Type and Frequency of Inaccurate Identifications and Classifications by Student Teachers

\begin{tabular}{lccc}
\hline $\begin{array}{l}\text { Nature of } \\
\text { grammatical errors }\end{array}$ & $\begin{array}{c}\text { Total number of } \\
\text { possible } \\
\text { identifications and } \\
\text { classifications }\end{array}$ & $\begin{array}{c}\text { Number of } \\
\text { erroneous } \\
\text { identifications and } \\
\text { classifications }\end{array}$ & $\begin{array}{c}\text { Percentage } \\
\text { frequency of } \\
\text { erroneous } \\
\text { identifications and } \\
\text { classifications }\end{array}$ \\
\hline Verb-type & 368 & 301 & 81.8 \\
Adjective-type & 92 & 70 & 76.1 \\
Noun-type & 138 & 21 & 15.2 \\
Sentence structure & 138 & 13 & 9.4 \\
\hline
\end{tabular}

Table 3 indicates that the greatest difficulty for student teachers was the identification and classification of verb-type grammar errors $(81.8 \%)$ as compared with other error types. Verb-type problems focused mainly on tense (e.g., past tense went instead of had been for action in the past with time reference indicated, line 5, Appendix C), and aspect (e.g., perfective had left rather than were left, line 3). With regard to adjectival forms, inaccurate identifications and classifications revolved around omission of articles (e.g., a few, line 8) or suffix ed (e.g., masked burglar, line 9). Student teachers showed greater awareness of problems relating to the other grammatical features, namely, noun-type and sentence-structure errors. They were generally able to identify misuse or omission of grammatical morphemes relating to singular/plural marking (e.g., valuables and not valuable, line 3) and to point out incomplete or fragmented sentence structures. Incomplete complex sentence constructions (e.g., When a burglary took place at a HDB flat in Hougang, line 1) were dealt with fairly competently by student teachers, who were able to point out that the subordinate when-clause is dependent on the main clause and thus unable to stand on its own.

\section{Explanation of Grammatical Rules}

Participants' scripts were also examined for explanations of the grammatical rules governing the use of specific features. Table 4 summarizes the frequency of student teachers' inaccurate answers in this area. As with Table 3, percentage frequencies of inaccurate answers were computed in relation to the maximum possible number of inaccurate explanations for each category of grammar error.

Difficulties in explaining verb-type rules again showed the highest frequency $(84.7 \%)$, followed by adjective-type and noun-type rules, with sentence structure rules reflecting the fewest problems for student teachers. The following are selected responses from student teachers in the area of greatest difficulty, verb-type rules. 
Table 4

Type and Frequency of Inaccurate Explanations of Grammar Rules

\begin{tabular}{lccc}
\hline $\begin{array}{l}\text { Nature of } \\
\text { grammatical error }\end{array}$ & $\begin{array}{c}\text { Total number of } \\
\text { possible } \\
\text { explanations }\end{array}$ & $\begin{array}{c}\text { Number of } \\
\text { erroneous } \\
\text { explanations }\end{array}$ & $\begin{array}{c}\text { Percentage } \\
\text { frequency of } \\
\text { erroneous } \\
\text { explanations }\end{array}$ \\
\hline Verb type & 368 & 312 & 84.7 \\
Adjective type & 92 & 65 & 70.6 \\
Noun type & 138 & 24 & 17.4 \\
Sentence structure & 138 & 12 & 8.7 \\
\hline
\end{tabular}

- Mr and Mrs Wu, owners of the flat, were shocked to find that their valuable which they were left on their table were missing the next morning (line 3).

- The verb were is redundant in this sentence (no further explanation given).

- The clause beginning with which does not require the verb were because it is redundant (why were is not required is not elaborated on).

- It is clearly understood that the event had taken place (unclear what the event refers to), hence the verb were is not needed.

- The verb missing does not go with were.

Student teachers showed awareness that the problem revolved around the phrase which they were left, but had difficulties in explaining the connection between the valuables of $\mathrm{Mr}$ and $\mathrm{Mrs} \mathrm{Wu}$, represented by which, and the fact that these had been left on the table.

- The couple did not realized what happen until the next morning (line 14).

- Did not indicates the action is not yet done; hence the present tense realize should be used instead of realized.

- Infinitive (?) not verb must follow verb in the base form.

- Did not realized is in the passive voice; the verb must be in base form.

- Past events require the use of past tense, thus happened.

- Need a verb in front of happen (no further reason given).

Although student teachers were aware that the verb following did has to be in the base form, they were unable to explain the reason. Passive and infinitive constructions were also misinterpreted. In the second part of the sentence, they had difficulty in explaining clearly the need for the perfective had happened, failing to see the distinction between a specific action that happened at a particular time in the past and the perfective aspect for something that happened with no specific time reference.

- Since then, they dare not to leave their valuable around their house where

burglars and thieves could get hold of (line 16).

- Unnecessary insertion of preposition to. 
The infinitive to (dare not to leave) was frequently misinterpreted as the preposition to.

The findings indicate that a relatively high proportion of student teachers' problems were verb-related, specifically in relation to time referencing through the appropriate use of features showing tense and aspect. Overall, student teachers had less difficulty with the identification and classification of errors than with the explanation of rules. They were generally able to identify the various parts of speech involved in an error and to use appropriate terms to classify the various error types although, as noted, confusion over some terms such as preposition and infinitive was evident. Knowledge of basic grammatical terms such as countable/uncountable nouns, transitive/intransitive verbs, or main/subordinate clause enabled student teachers to begin describing and discussing the errors that they identified. The earlier course, which had introduced them to the basic concepts and terminology required for the study of English grammar, was useful in providing the necessary foundation for identifying the errors.

Student teachers commented that having access to the error-type terminology introduced in the course gave them the confidence to begin talking about the errors that they identified and provided them with a sharper analytical focus. Essentially, what this approach furnished was the metalanguage to help student teachers explain and describe the nature of the errors identified and also to improve their analytical skills for close examination of the grammatical problems in children's writing.

Difficulties in explaining the rules revealed the extent of student teachers' ability fully to grasp specific grammatical concepts, in particular those relating to tense and aspect, and appropriately to connect specific grammatical features with various parts of a sentence in specific contexts. There was also variability in the degree of precision in the use of specific terminology, with potential to demonstrate confusion about particular features relating mainly to verbs and verb groups. Rules governing sentence structure constructions proved the least problematic for student teachers.

\section{Effect on Student Teachers}

Student teachers' feedback was elicited before and after the course in order to gain a better perspective on the effect of such a course on their level of skills and on the gains achieved. The following sections elaborate on student teachers' feedback and comments in specific areas.

Concerns before the course. Student teachers' concerns before the course centered mainly on personal inadequacies, course expectations, and skills in grammatical explanation. They expressed personal insecurity over their lack of grounding in English grammar and their fear of not being able to deal confidently with their pupils' errors, particularly with respect to the skill of giving effective explanations "in the jargon and terms" required. Their initial 
personal perceptions of the course were about potential boredom and the expectation of "a lot of rote learning."

Feedback after the course. Student teachers generally welcomed sensitization to the process of paying close attention to the specifics of error identification, analysis, and explanation with respect to grammatical problems in children's writing. Feedback generally focused on specific gains related to error identification and analysis, the advantages of using actual pupils' texts in the course, the administration of the course, and personal benefits.

Positive responses of student teachers included the value of the three-step table as a framework to begin framing a grammatical analysis systematically through a step-by-step approach that sharpened their skills "in picking out or identifying grammatical errors now as compared to before" and in becoming "more aware of the errors that are commonly made." With regard to the explanation of errors, the gains included clarity and precision in explaining "in detail," consistency among teachers in the use of a "common language for all professional teachers," a deepening awareness of the language, and the value of using real-life pupils' work as authentic examples from which to learn. The overall satisfaction with course administration revolved around expressions of appreciation for the well-planned organization, pace, and delivery of the course, mock tests with valuable immediate feedback, and useful handouts for reference. On a personal level, student teachers felt that their own command of the language improved as they became more aware of and sensitive to "common errors that even I make as a grown-up."

Feedback from tutors. The original team of four tutors who taught the course also provided valuable feedback. Among the strengths of the course, they highlighted not only the opportunity for students to be involved in contextualized grammar analysis, but also tutors' enhancement of their own personal grammar skills. As well, tutors drew attention to the exposure of student teachers to text structures and language features from varied texts, and to the provision of just-in-time help leading to personal growth in awareness of grammar and its role in managing pupils' errors in writing.

Areas that required attention included the course coverage and the nature of assessment. There were suggestions to tailor the course content such as not just to teach to the test in order to help students pass the final assessment.

\section{Recommendations}

Based on feedback from staff and students, a number of recommendations may be proposed for further improvement of the course. These include the following.

It is acknowledged that although the correction of errors is easily handled by first-time teachers, even thorough identification, classification, and exemplification of errors represent just half the picture. There remains a need to enable students to internalize the rules in order to use appropriate grammati- 
cal forms in their own writing. This is undoubtedly a complex task and not one to be easily resolved through a one-off course. It would, therefore, be beneficial for tutors and the course coordinator to continue thinking through strategic means to move collaboratively toward this objective.

Moreover, there were suggestions for more time and practice to work on more samples of texts in order to apply the approach of error identification, classification, and explanation to additional types of texts written by school pupils. This is something that could be implemented by a more judicious use of class time and through balancing the need for explicit and guided instruction with in-class practice. The online delivery format can also be further exploited in this area in order to maximize the allocation of time for practice exercises, which can be completed out of class and subsequently followed up in class for further clarification should the need arise. At present, answers to in-class tutorial exercises are not posted on online through Blackboard, but rather are discussed only face to face in class with tutors. Similarly, there is room to provide extra worksheets and further tasks or activities that students can easily access from Blackboard, together with answer keys posted at strategic times to facilitate self-study and review.

Related to the question of time constraints is the issue of content coverage in the time span of the course. The original course design was researchdriven: it offered selective emphases on aspects of grammar where action research had indicated that Singapore students had problems. In this spirit, it could be useful to review the course content for areas of unnecessary overlap and to work wherever possible toward integrating various aspects of grammar instead of treating them as isolated units. This could also help students more clearly see interconnections among elements of the complexity of English grammar.

One participant recommended the possibility of treating errors made in oral communication as well as in writing. As first designed, the course set out to focus only on errors in pupils' writing, which was a realistic goal given not only the time constraints, but also the nature of the course itself, which essentially built on an earlier course that provided a foundation in basic English grammar. Extending the course to include typical errors in oral communication would thus probably be unrealistic. Still, a separate course to handle the area of oral grammar and oral communication skills might be appropriate.

Assessment was another area of concern, with a suggestion that instead of a $100 \%$ summative test, periodic diagnostic tests or continual assessments throughout the course might enable participants to identify their own specific weaknesses. In this connection, it is noteworthy that, as indicated above, the initial assessment format did include two formative in-class mock tests held at strategic points during the course and intended to offer a developmental dimension: identifying problems and providing practice 
liberated from the pressure of formal tests with recorded grades. However, it was suggested that the number of formal assessments might be increased to two instead of one, which would reduce the weighting of the final assessment. In the words of student teachers themselves, "I strongly feel that examination is really not necessary. Another suggestion would be to have class tests. It is pointless to cramp so many things and have a test at the end. Defeats the whole learning process," and, "Assessment can be done through weekly assignments (short ones) e.g., weekly exercises. It's less stressful that way."

Using more alternative modes of formal and informal assessment, or monitoring tasks and activities, could also provide a wider range of instruments on the basis of which to gauge student teachers' ability, which might also reduce the tendency for tutors to merely teach to the test, as is commonly observed in some courses.

\section{The Way Ahead}

The needs of this group of non-English major student teachers training to become English language instructors proficient in the language are indeed very real, and the complexity of the situation cannot be underestimated. There is a fine balance between teaching and testing: instructors must guard against over-testing without providing sufficient time to internalize complex rules and to understand their application or misapplication in specific contexts. Such caution is also relevant when considering options for other modes of assessment, with a clear need to distinguish between formative and summative assessment so that neither is overemphasized at the expense of the other.

The effect of time constraints on content coverage might also be reexamined with a view to implementing judicious use of time with respect to the key content areas to be covered in the duration of the course. Optimal use of curriculum content time could lead to adjustment and/or reorganization of content, so as to align grammar topics that are related to each other and, where possible, reduce unnecessary overlap or repetition.

Overall, the approach adopted by the course promotes the strategy of noticing specific language features (Schmidt, 1990; Carter, 1997; Fotos, 1993), a practice recommended as "critical to subsequent processing of the forms" (Schmidt, p. 139). The focus on error identification and text analysis in the course is consistent with a move toward "grammar consciousness-raising" tasks (Fotos, p. 387) apt to enhance "learner awareness of particular linguistic features" (Rutherford \& Sharwood Smith, 1985, p. 275) and empower students to manage their own learning and understanding. Against this background, it may be argued that making more time and practice available to student teachers for mastering text analysis would further the approach by 
enhancing both their analytical skills and their confidence in explaining and describing grammar problems in children's writing.

Moreover, the need to develop student teachers' own understanding of the concepts and rules of English grammar should not be overlooked. Until they are clear as to what grammatical features are in play and how these affect the comprehensibility of pupils' texts, there is little value in progressing to the stage of discussing and explaining the interaction of various grammatical features, let alone the rules involved. Thus having student teachers from time to time carefully examine and articulate what contributes to grammatically flawless constructions by children, rather than focusing only on problematic examples, could provide a useful contrast whereby major differences and key errors could be highlighted and made more explicit.

A central goal of the course's close analysis of the types of problems children face in constructing texts is to move beyond attention to merely discrete, surface-level grammatical items, and thereby to resituate grammar instruction in specific contexts of textual production and language use. Grammatical concepts are taught by providing students with adequate definitions and with diverse examples and non-examples carefully discussed in the context of the children's own use of language. This approach offers an opportunity to exploit the grammars that pupils have in fact internalized as a way of teaching the grammar of standard English through examining error types and the frequency and patterns of problems that surface in pupils' own work.

When given responsibility for finding, diagnosing, and correcting their own errors and those of their peers, pupils will over time become able to find patterns that highlight and enhance their efforts at overcoming these errors. However, attention to the analysis of pupils' errors may be more effective when individualized at a personal level so as to cater to specific weaknesses and misunderstandings of grammar rules in particular contexts. Thus there is a need for teachers to balance such individualized work with whole-class instruction in grammar and use in the language curriculum.

\section{Conclusion}

The approach discussed in this article offers a means of empowering language teachers to help pupils with the grammar problems evident in their own writing. It is acknowledged that any attempt neatly to simplify and categorize sentence-level errors may overlook some of the essential complexity of the English language with its overlapping areas and fuzzy boundaries. Consequently, there remains a need for further revision and adaptation of the three-step approach recommended here so as to accommodate a wider range of more complex errors. Nevertheless, close, systematic, and methodical textual analysis is beneficial by focusing attention 
not only on the type and nature of the errors made, but also on the effort to understand them from the viewpoint of the pupil. Indeed, as Carter (1997) reminds us, "language in the classroom is not to be encountered wholly by unconscious, implicit and indirect means" but also by a process of learning to "see through [emphasis in original] language in a systematic way and to use language more discriminatingly" (p. 34).

Still, although close examination of children's writing, as opposed to mere textbook explanations of grammatical concepts, can prove beneficial to both teachers and learners, this initiative will presumably be effective only if pupils already know the concepts. A pupil-directed approach, therefore, must focus on the learners' specific knowledge, needs, and weaknesses. Texts generated by learners themselves provide access to the existing grammatical knowledge (or lack of it) possessed by young learners. Teachers can unlock this resource of knowledge if they are sufficiently aware of and sensitive to the challenges pupils face when writing. Thus grammatical consciousness-raising is vital for building language teachers' awareness of the difficulties faced by the children they are teaching. Exploring grammatical problems in children's own writing reinforces the importance of studying grammar not in isolation, but in its location "in use and in its creation of contextual meanings" (Carter, 1997, p. 30), which is ultimately more needsoriented, problem-focused, and learner-centered. Anything less will shortchange our pupils and diminish the significant role that language teachers can play both in developing a fuller understanding of the intricacies of language use and in instilling confidence in language learners.

\section{The Author}

Caroline Ho is an assistant professor of English language and literature in Nanyang Technological University, Singapore. Her research interests include language pedagogy and ICT in EL teaching and learning. Her doctorate in applied linguistics from the University of Birmingham (UK) is in the area of electronic discourse analysis.

\section{References}

Carroll, S., \& Swain, M. (1993). Explicit and implicit negative feedback: An empirical study of the learning of linguistic generalizations. Studies in Second Language Acquisition, 15, 357-386. Carter, R. (1997). Investigating English discourse. London: Routledge.

Corder, S.P. (1967). The significance of learners' errors. International Review of Applied Linguistics, 5(4). Reprinted in J.C. Richards (Ed.), (1974) Error analysis: Perspectives on second language acquisition (pp. 19-27). London: Longman.

Corder, S.P. (1981). Error analysis and interlanguage. London: Oxford University Press. Crystal, D. (1998). Rediscover grammar. London: Longman.

Fotos, S. (1993). Consciousness-raising and noticing through focus on form: Grammar task performances versus formal instruction. Applied Linguistics, 14, 385-407.

Gopinathan, S. (1999). Language policy changes 1979-1997: Politics and pedagogy. In S. Gopianthan, A. Pakir, W.K. Ho, \& V. Saravanan, (Eds.), Language, society and education in Singapore: Issues and trends (pp. 19-44). Singapore: Times Media Private.

Ho, M.L.C. (2005). Exploring errors in grammar: A guide for English language teachers (2nd ed.). Singapore: Pearson Longman. 
Lim, S.C. (2000). The English language syllabus 2001: Change and continuity. Teaching of English Language and Literature (TELL) 16(2), 9-14.

Ministry of Education, Singapore. (2001). English language syllabus 2001 for primary and secondary schools. Singapore: Author, Curriculum Planning and Development Division.

Rutherford, W., \& Sharwood Smith, M. (1985). Consciousness-raising and universal grammar. Applied Linguistics, 6, 274-282.

Schmidt, R. (1990). The role of consciousness in second language learning. Applied Linguistics, 11, 129-158.

Selinker, L. (1992). Rediscovering interlanguage. London: Longman.

Trahey, M., \& White, L. (1993). Positive evidence and preemption in the second language classroom. Studies in Second Language Acquisition, 15, 181-203.

White, L., Spada, N., Lightbown, P., \& Ranta, L. (1991). Input enhancement and L2 question formation. Applied Linguistics, 12, 416-432.

Willis, D. (1991). Collins COBUILD student's grammar. Melbourne: HarperCollins.

\section{Appendix A \\ Table for Analysis}

Identification of error Definition and error classification Explanation of rule

\section{Appendix B}

List of Terminology: Classification of Error Types

This list provides samples of suggested classifications of error type.

- Omissions: Is there something missing? Article: He hit ^ car.

- Additions: Is there an unnecessary addition?

Overgeneralization or Unnecessary insertion.

- Suffix: past tense marker -ed: putted for put

- Suffix: plural marker -s: Apparatuses for Apparatus.

- Wrong or inappropriate combination: Is there something which shouldn't go with another?

Noun information is uncountable and must therefore take a singular verb: Your information are false.

- Inappropriate construction: Is there an incomplete/inappropriate construction?

Fragmented/incomplete sentence: Because I didn't like Law. I dropped it in my

1st year.

- Run-on sentence: When I was in school, I studied very hard in every subject but I cannot success in everything because I weak in every subject and father try to stop learning.

- Misordering /Inversion: Is there a wrong order of items?

Subject-verb inversion: Now I don't know why are we taught this. 


\section{Appendix C}

Q1. Read the following text written by a student. In the table provided, identify the grammatical errors, classify the type of errors, and explain the rules which have been violated. Use one row for analysis of each error type. Repeated errors are to be ignored.

It was 2.30 in the morning. When a burglary took place at a HDB flat in Hougang. Mr and Mrs Wu, owners of the flat, were shocked to find that their valuable which they were left on their table were missing the next morning.

5 The couple said that they had been to a wedding dinner the night before and returned home around midnight. They had left their valuable which included a handbag and few pieces of jewelleries on a table and went to bed after doing so due to exhaustion.

10 The burglar had climbed into the bedroom through the window. The mask burglar then crept across the room to the table and grabbed the valuable. Before he could do so, the Wu's pet hound woke up from its sleep and barked fiercely at him. Even though the barking of the dog was loud enough to alert the neighbours of $\mathrm{Mr}$ and $\mathrm{Mrs} \mathrm{Wu}$. The couple was still sleeping soundly. The

15 couple did not realized what happen until the next morning when the burglarhad already steal the valuable. Mr and Mrs Wu went to reported the incident to the police. Since then, they dare not to leave their valuable around their house where burglars and thieves could get hold of. 